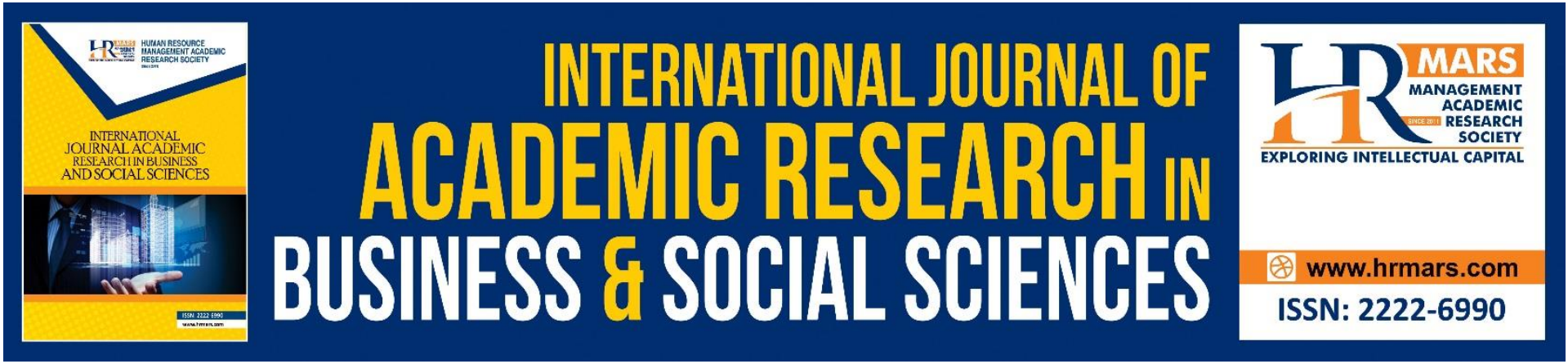

\title{
Hate Speech and LGBT Media Framing Effects among Community
}

\author{
Julia Wirza Mohd Zawawi \& Hamisah Hasan
}

To Link this Article: http://dx.doi.org/10.6007/IJARBSS/v11-i19/11726 DOI:10.6007/IJARBSS/v11-i19/11726

Received: 19 October 2021, Revised: 22 November 2021, Accepted: 30 November 2021

Published Online: 15 December 2021

In-Text Citation: (Zawawi \& Hasan, 2021)

To Cite this Article: Zawawi, J. W. M., \& Hasan, H. (2021). Hate Speech and LGBT Media Framing Effects among Community. International Journal of Academic Research in Business and Social Sciences, 11(19), 180-190.

Copyright: @ 2021 The Author(s)

Published by Human Resource Management Academic Research Society (www.hrmars.com)

This article is published under the Creative Commons Attribution (CC BY 4.0) license. Anyone may reproduce, distribute, translate and create derivative works of this article (for both commercial and non-commercial purposes), subject to full attribution to the original publication and authors. The full terms of this license may be seen at: http://creativecommons.org/licences/by/4.0/legalcode

Special Issue Title: Youth and Community Wellness, 2021, Pg. 180 - 190

http://hrmars.com/index.php/pages/detail/IJARBSS

JOURNAL HOMEPAGE

Full Terms \& Conditions of access and use can be found at http://hrmars.com/index.php/pages/detail/publication-ethics 


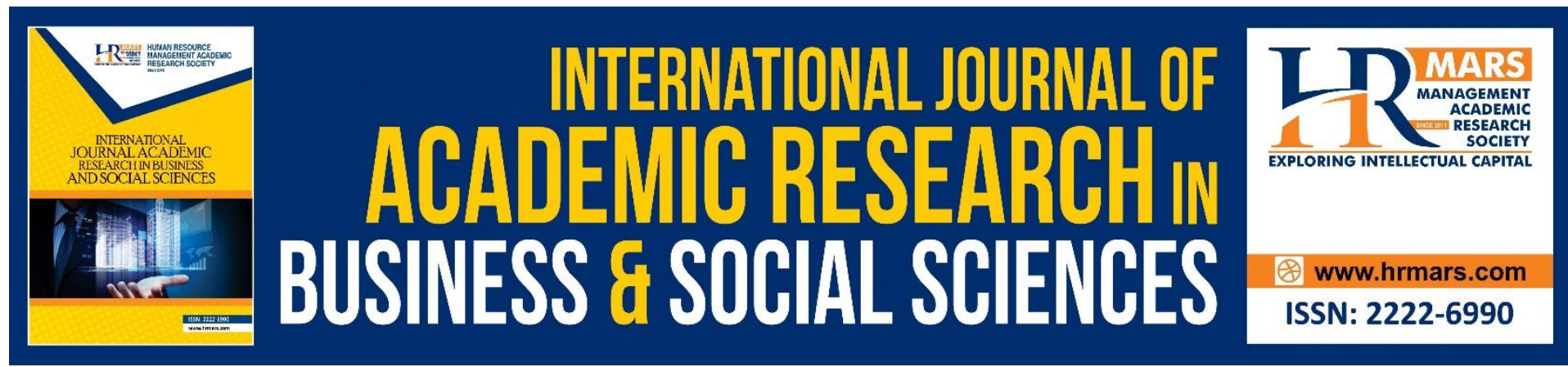

\title{
Hate Speech and LGBT Media Framing Effects among Community
}

\author{
Julia Wirza Mohd Zawawi ${ }^{1} \&$ Hamisah Hasan ${ }^{2}$ \\ ${ }^{1}$ Institute for Social Science Studies, Universiti Putra Malaysia, 43400 Serdang, Selangor, \\ ${ }^{2}$ Taylor's University, 47500 Subang Jaya Selangor, Malaysia. \\ Email: wirza@upm.edu.my
}

\begin{abstract}
The development of communication technology facilitates the users to get fast and easy information. Furthermore, with this platform all users will create and upload news content, and interested readers can get it through social media. The attainability can be seen to have either negative or positive possibilities. This study conducted took the example of Lesbian, Gay, Bisexual and Transgender (LGBT) issue as the core on how negative media content display gives different effect whether to the change of attitude and behaviour of an individual. Using experimental study approach, this study will have some main objectives namely to see the hate speech display effect related to LGBT on individual. Second, compares positive or negative message or news display on change of attitude and behaviour of an individual. The analysis using descriptive analysis and Paired Sample T-Test and Analysis of Variants (ANOVA) will idenfity how far the hate speech message display effect on an individual. The findings show that positive frame gives effect compared to the negative frame on readers' attitude and behaviour. Besides that, significant change towards the change of attitude compared to the change of behaviour.
\end{abstract}

Keywords: Hate Speech, Frame Setting, Knowledge, Attitude, Behaviour

\section{Introduction}

Displays and concept inquiry related to hate speech is not new in social science, and pioneered by the sociological study years ago. The term hate speech started with the oppression towards the black and women communities. Hate speech started from a prejudice from some groups towards another group. This prejudice then created hindrance that brought social oppression and finally brought to the form of a law and policy to object hate speech (Mondal et al., 2017).

The situation heightens with the development of the internet and social media that give freedom to the society to speak their mind through the media. This situation gives them opportunities to freely giving opinions without any law restrictions. The freedom of speech is still in use where various nation's laws do not have the right to restrict them from giving opinions in the social media. Most of the approaches taken by some social medias are to restrict the sharing of content that has the element of hate speech. Recently, through observation and study by Mondal et al (2017), hate speech display through social media is a 
concern and widespread. Facebook and Twitter use the approach of restricting the hate speech sharing through these mediums.

Based on the Community Empowerment for Progress Organisation (CEPO) (2016), hate speech usually attacks individuals or groups for the difference of races, religions, sex or sexual orientation. For example, the Lesbian, Gay, Bisexual and Transgender or LGBT. The difference of sexual orientation is prohibited by some countries especially Muslim countries like Malaysia. Shafie, et al (2018), explained that LGBT is a psychological problem caused by the tendency of thinking and behaviour, personality and identity of an individual that relates to manhood and womanhood.

The taboo issue like this is considered normal to be discussed especially in the social media. Maximum exposure capacity to social media or internet has made the exposure to become widely open without any prevention or restriction. An individual is free to express his personal opinion in LGBT issue, whether to critic or support the discussion related to LGBT.

\section{Literature Review}

\section{Hate Speech and Social Media}

Hate speech was once something unpredictable and unexpected because of the limitation of information technology. In the recent years, the sharing of information that contains hate speech messages are widespread due to the maximum usage of social media around the world. The freedom of using the social media contributes to the increase of hate speech. Community Empowerment for Progress Organisation (CEPO) explains that hate speech is an action that can affect other individual's emotions. Hate speech can be delivered in various forms such as texts, images, films, songs and many more. Some scholars explain that hate speech is a communication concept that include prejudice and outside stimulus.

The discussion on hate speech is something very subjective and has a different understanding from various perspectives. The increase spread of hate speech through social media is closely related with ethical understanding that is spurs to the negative values, which is against the normal human noble values. Hate speech is spurs by a hate emotion. Hate emotion does not only include emotion but more to the action that oppose to an individual's attitude, behavior and activity (Drodzdz, 2016).

While hate speech can be found through social media, Facebook and Twitter introduced their own definitions for hate speech and suitable approach to handle the hate speech issue. Facebook's rule restricts bully, harassment and threat whether in texts or visual. While Twitter in its statement in 2015 , social media medium restricts speech that contains criminal and violence to other people despite their race, religion, sexual orientation or gender.

Avoiding Discrimination and Hate Speech in Media Guidebook (2018) explained that there are some factors that cause the widespread of hate speech through media especially the social media. Among them are the bias reporters or individual who wrote on an issue and the tendency to report negative information. This guideline also stated the influencing factors. First is the malpractice on delivery of information. Second is the bias on the content and decision making.

\section{Framing and Hate Speech}

Hate does not only involve emotional essence, but it also involves natural feeling that rejects individual's behaviour, language or any activity. Natural hate determines the purposes of rejection, whether of threat to one party or because of the rejection towards other individual. 
Subjective concept and definition related to hate speech is always brought up by the recent mass media especially the new media (Drozdz, 2016).

Drozdz (2016) explained that, it understandable that the main role of the media is to provide information to the society. Competition with the existing news source and the development of technology creates evolution to the information sharing by the media. In accordance with this role, the media is seen to actively working to create reality, which is delivering latest news and information faster to the readers. Therefore, drastic changes can be seen either to the creator or the news receiver.

\section{Framing Basic Concept}

There are various assumptions and questions by the scholars and media practitioners on how the content from the media in the form of hate speech can be regarded as a threat to the society. Phadke and Mitra (2020) explained that the media framing concept which is widely discussed by the communication scholars is the most synonym context with this situation. He explained that framing does not only refers to the news from the conventional media per se buat also from the new media. Combining the framing concept from a few scholars, framing refers to highlighting something in a perspective, by emphasizing some aspects, at the same time emphasizing the opposite perspective which is finally influencing its interpretation.

He also explained that through the study conducted by the previous scholars, they identified a few frames as the continuity to the existing study of framing. This study is widely used by the sociology scholars to study matters related to framing. The continuity consists of three basics in framing namely (i) diagnostic, by identifying social movement problem; (ii) prognostic, that offers solution and (iii) motivational that functions as action.

\section{Frame effect and Hate Speech on Behaviour and Attitude}

Message content frame is not only used and applied in the mass media studies, but regarded as one of the communication strategies used to influence evaluation, behaviour and attitude. And it is framed as a benefit or consequence in an action (Shan et al., 2020).

Shan et al (2020) through a study related to marketing communication, explained that negative framed message emphasized on cause and effect of not buying the product or service, while a positive framed message emphasized on the benefit of buying the product or service. Previous studies gave diverse views. Some studies proved that positive framed message has dominant persuasive effect. And some studies proved the strength of negative framed message especially in marketing communication.

Framing effect process as explained by Zawawi et al (2019) explained that studies related to framing effect have close association with psychological element. An individual will always think and make a decision with what he sees and obtains around him. In psychology, this process is known as information processing. This statement is supported by a study done by Lee and McLeod (2020). Framing effect study has been translated and interpreted in social cognitive information processing frame. In the beginning, media frame and news frame tend to determine the suitable thought with the existing frame thought. This information processing will directly or indirectly bring to the change of attitude and behaviour of the reader.

\section{Methodology}

This study uses experimental methodology approach to see the positive framed and negative framed news on readers' change of attitude and behaviour. Experimental study is suitable as 
a method for testing study on the effectiveness of a stimulus. Experimental study is usually used for study on cause and effect. Therefore, this study uses LGBT issue as the key of creating stimulus.

\section{Stimulus}

Stimulus is one of the instruments needed in an experimental study and stimulus can be used in many forms either visual or printed. In this study, the stimulus created is visual. News materials in videos and printed news quotes from certain websites are compiled and produced in a form of video. A help from an expert in creating the video made it more suitable and relevant to be used.

The stimulus video created consists of three parts. The first video is identified as positive framed, which displays the news on different views in LGBT minority oppression and what should have been done to help this group. The second video displays a negative framed, the effect of active LGBT involvement to the society and nation. The third video is a neutral framed, which displays neutral messages and news such as the concept and definition on LGBT without displaying negative or positive elements of LGBT.

\section{Procedure of Experimental and Sampling}

The participants in this experiment were students of Bachelor of Communication Universiti Putra Malaysia (UPM) aged between 21 to 35 years old. There were 54 students of Bachelor of Communication UPM involved in this experimental study. In the beginning, 60 students were chosen but only 54 attended this experimental study. 60 names were chosen randomly and divided into three groups namely Treatment Group (T1), Treatment Group 2 (T2) and Controlled Group (T3) randomly. The name list from 1 to 20 was grouped in group T1, 21 to 40 in group T2 and 41 to 60 in group T3.

The participants were divided randomly to ensure the division to each group depends on chance not on the researcher. This to ensure the sample chosen did not go through a bias process. ANOVA test was done to ensure the division of participants for the groups were equal. Table 1 shows significant difference for the three groups with the value obtained is $F$ $(2,49, p>0.05)=0.061$ for knowledge, $F(2,48, p>0.05)=0.423$ for behaviour and $F(2,49$, $\mathrm{p}>0.05)=0.369$ for attitude.

Table 1: Result of ANOVA Test

\begin{tabular}{lccccccc}
\hline \multirow{2}{*}{ Frame } & $\boldsymbol{N}$ & \multicolumn{2}{c}{ Knowledge } & \multicolumn{2}{c}{ Behaviour } & \multicolumn{2}{c}{ Attitude } \\
\cline { 3 - 8 } & & Mean & Sig. & Mean & Sig. & Mean & Sig. \\
\hline Positive & 19 & 7.18 & 0.941 & 3.52 & 0.657 & 4.48 & 0.693 \\
Negative & 17 & 7.27 & & 3.42 & & 3.99 & \\
Neutral & 16 & 7.11 & & 4.11 & & 4.31 & \\
\hline
\end{tabular}

\section{Experimental Design}

The suitable methodology chosen is important to ensure the methodology approach is suitable and accurate with the research conducted. As one of the ways to test the effectiveness of the hate speech approach, the accurate approach is an experiment.

One of the factors of choosing experiment as the methodology is, to test the hypotheses that determines the relationship of cause and effect. This is supported by Gay (1996) who stated that experiment is the only methodology that study the relationship of cause and effect. Other than that, through experiment methodology approach, the 
researcher is able to manipulate the variables and makes decision to give a suitable treatment.

Since the methodology approach used was experiment, the total number of respondents and sample chosen were different with other methodology approaches such as survey that needed the sample to represent the total of population.

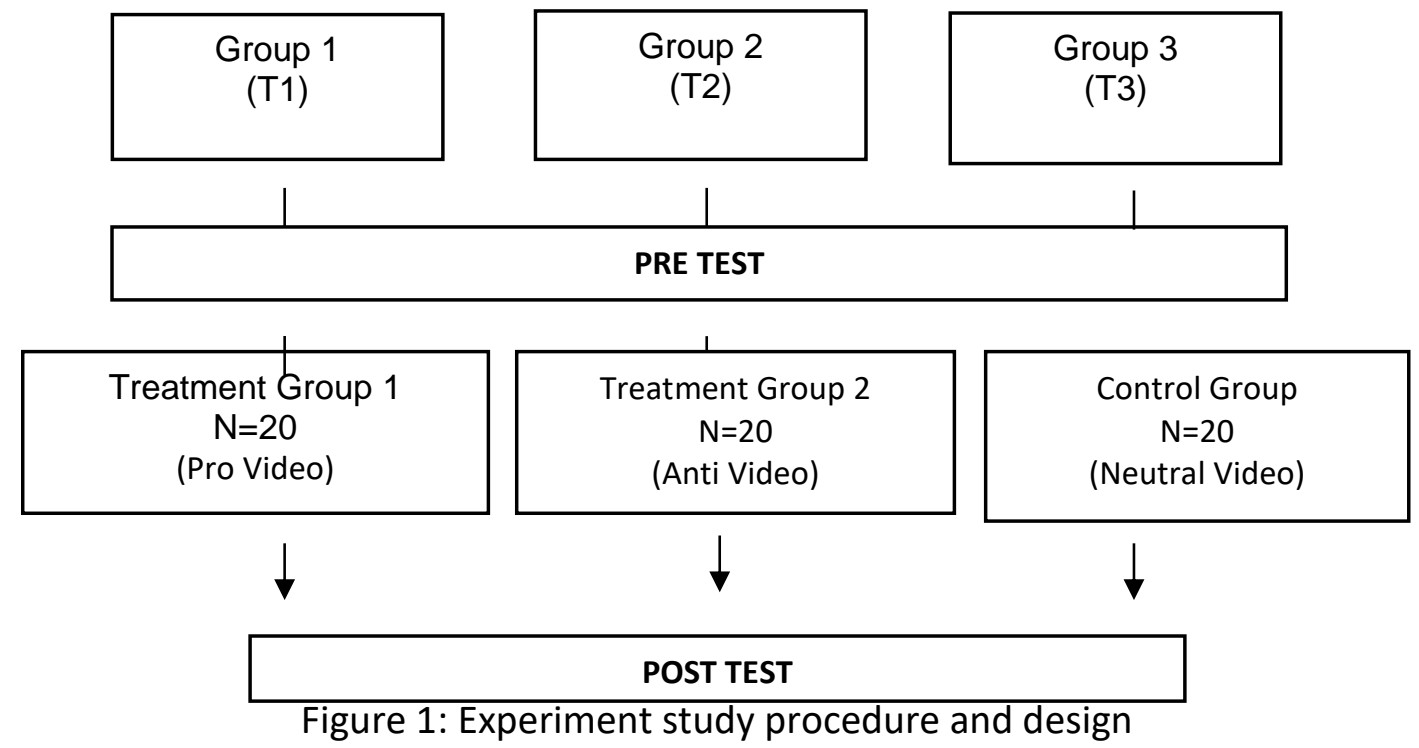

\section{Reliability and Validity}

Validity test was done for instrument that was used in this study namely questionnaire and stimulus video. Validity was used to ensure the measurement or indicator used was suitable or accurate with the study conducted (Jasmi, 2012). Therefore, to ensure each measurement and indicator have all the characteristics in the concept measured, instrument and stimulus were evaluated by the experts in communication field.

Other than validity, reliability test was also conducted to ensure the consistency and stability of the measurement in the questionnaire (Azmi; 2012). The value over 0.7 was accurate to ensure consistency and accuracy of each question in the variables in the study conducted.

Table 2: Variables of Cronbach Alpha Value

No. Variables Cronbach Alpha Value

\begin{tabular}{lll}
\hline A1 & Knowledge & 0.745 \\
A2 & Behavior & 0.726 \\
A3 & Attitude & 0.752 \\
\hline
\end{tabular}

\section{Result and Discussion}

For this study, the researcher used Paired Sample T-test to test the effectiveness and comparison of positive and negative news frame related to LGBT issue on readers' change of behaviours and attitudes. 
Demography

Table 3: Participants Demography Characteristics

\begin{tabular}{|c|c|c|c|}
\hline Demographics & Frequency & Percentage (\%) & $\begin{array}{r}\text { Mean/ Std } \\
\text { Deviation }\end{array}$ \\
\hline \multicolumn{4}{|l|}{ Gender } \\
\hline Male & 17 & 31.5 & \\
\hline Female & 37 & 68.5 & \\
\hline TOTAL & 54 & 100 & \\
\hline \multicolumn{4}{|l|}{ Age } \\
\hline $18-22$ & 15 & 27.8 & \\
\hline $23-27$ & 36 & 66.7 & $1.82(0.46)$ \\
\hline $28-32$ & 1 & 1.9 & \\
\hline $33-37$ & 2 & 3.7 & \\
\hline TOTAL & 54 & 100 & \\
\hline \multicolumn{4}{|l|}{ Religion } \\
\hline Islam & 39 & 72.2 & \\
\hline Buddha & 5 & 9.3 & $1.51(0.93)$ \\
\hline Hindu & 7 & 13.3 & \\
\hline Christian & 3 & 5.6 & \\
\hline Others & 0 & 0 & \\
\hline TOTAL & 54 & 100 & \\
\hline \multicolumn{4}{|l|}{ Ethnic } \\
\hline Malay & 39 & 72.2 & \\
\hline Chinese & 6 & 11.1 & $1.46(0.82)$ \\
\hline Indian & 8 & 14.8 & \\
\hline Others & 1 & 1.9 & \\
\hline TOTAL & 54 & 100 & \\
\hline
\end{tabular}




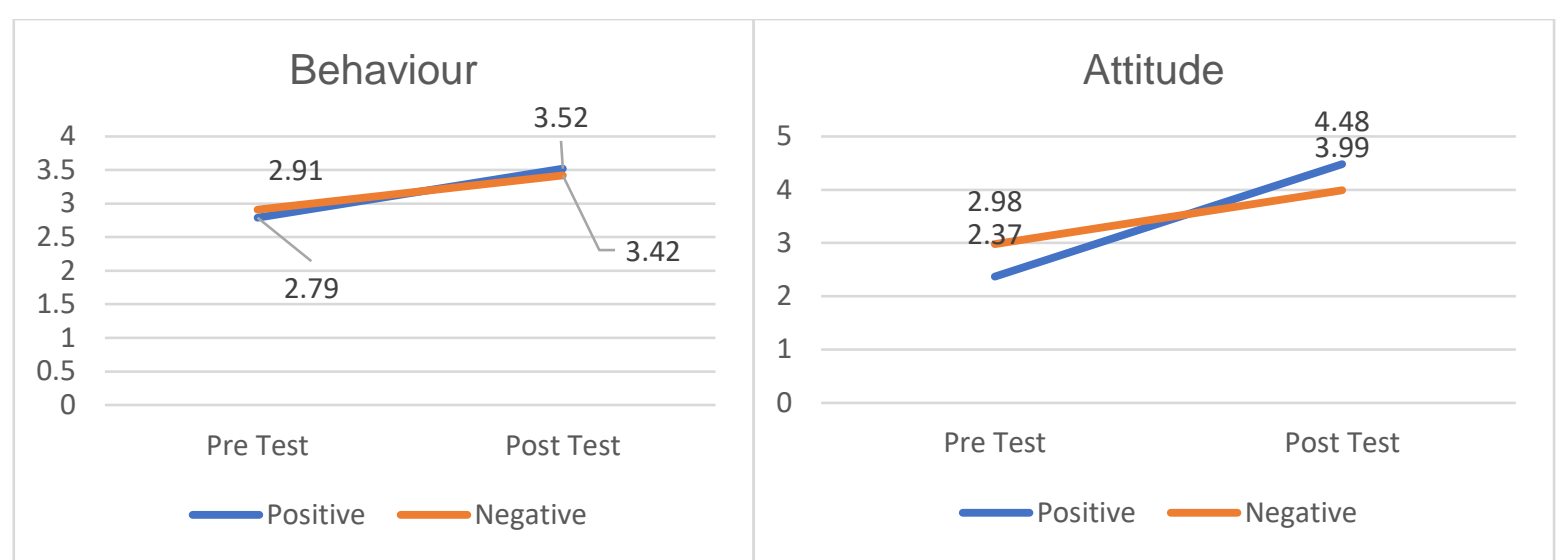

Figure 2: The effect of positive and negative frame on readers' attitude and behaviour.

Figure 2 shows the difference effects of positive and negative news frame on readers' attitude and behaviour. Overall, both positive and negative frames show increment to the readers' change of attitude and behaviour. However, from Figure 2 we can see that positive frame is more effective than negative frame. For the change of behaviour (positive frame $M=3.52$, negative frame $M=3.42$ ), while for attitude (positive frame $M=4.48$, negative frame $M=3.99$ ).

Table 4: Pre and Post Paired T-Test Result

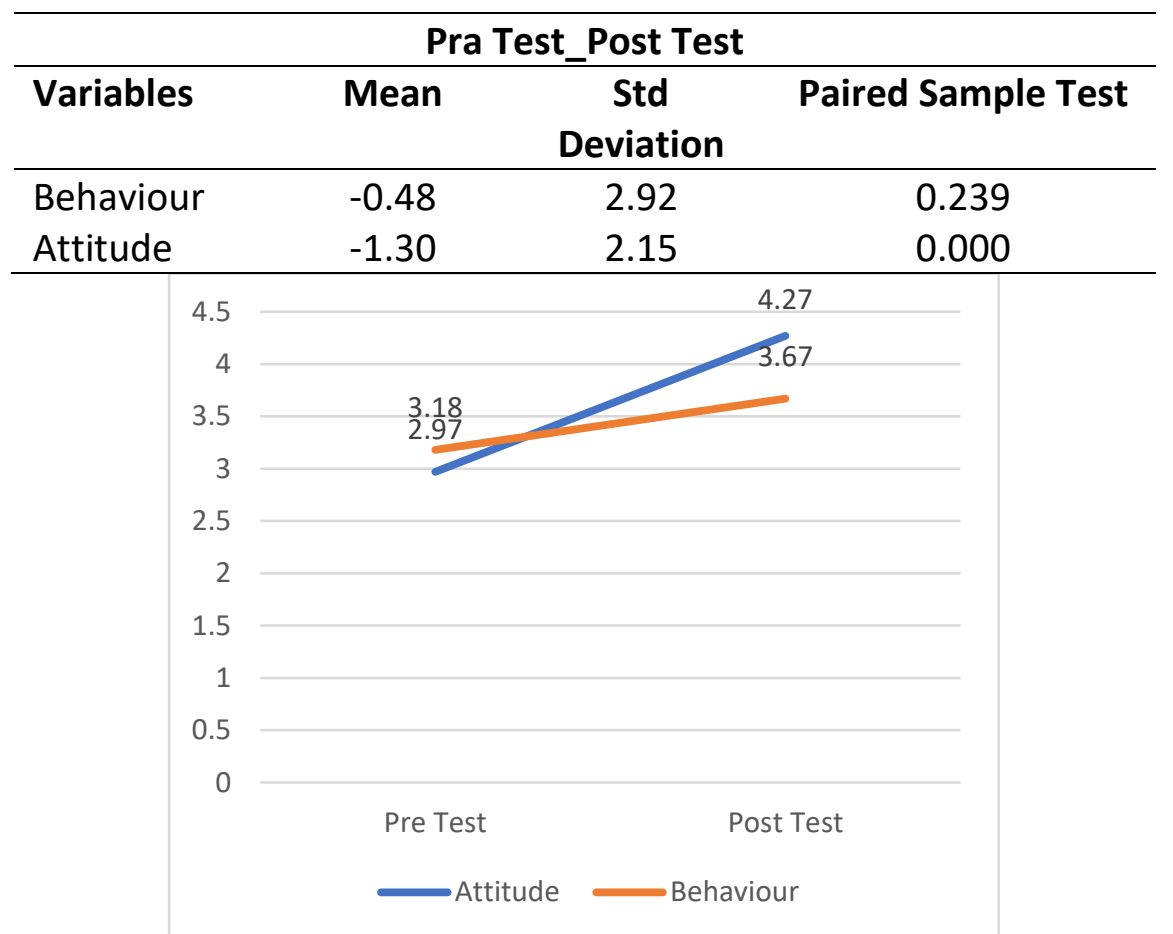

Figure 3: Comparison between Pre and Post Paired T-Test Result

Table 5: Pre and Post Test Variables Descriptive Analysis

\begin{tabular}{lcccc}
\hline & \multicolumn{2}{c}{ Behaviour } & \multicolumn{2}{c}{ Attitude } \\
\hline & Pre & Post & Pre & Post \\
\hline Positive Frame & $2.37(1.14)$ & $4.48(1.68)$ & $2.79(1.72)$ & $3.52(2.27)$ \\
Negative Frame & $2.98(1.45)$ & $3.99(1.82)$ & $2.91(1.95)$ & $3.42(2.60)$ \\
\hline
\end{tabular}

For the second objective was to make a comparison on the change of readers' attitude and behaviour between pre and post after the LGBT news display. Table 5 shows that there are 
significant pre and post exposed with LGBT frame on the change of attitude either positive or negative, with pre $(M=2.9, S D=1.41)$ and post $(M=4.2, S D=1.74)$ with $t(48)=-1.191, p=0.000$ $(p<0.05)$. However, for the change of behaviour, there is no significant difference in pre and post when exposed with positive or negative frame, with $(M=3.2, S D=1.81)$ and post $(M=3.7$, $\mathrm{SD}=2.28)$ with value $\mathrm{t}(50)=-4.251, \mathrm{p}=0.239(\mathrm{p}>0.05)$.

\section{Discussion and Future Perspective}

The influence of mass media either conventional media or new media as the medium of message delivery to the people is still relevant. The difference is the mediator used in delivering them. The issue it brings can also be the factor of the effectiveness of the news display through media.

Based on the study findings, news display or LGBT messages delivery give more effect to the readers' change of attitude and behaviour compared to the negative news. McClure, White and Sibley (2009) explained that framing effect occurred when there were two message displays that logically produce different effects. For example, when the readers are often exposed to the positive frame, they will receive positive cause and effect. LGBT issue especially is seen in a very negative perspective but from a different context, readers are easily influenced and this will give some effects if LGBT news frame is delivered from the positive perspective. For example, ways to help the LGBT group from continually exposing themselves in this unhealthy situation. Or as an Islamic country, teaching approach should be instilled in displaying this kind of sensitive news.

Levin (2005) conducted a study and stated that positive form of message approach is very relevant in marketing field, by introducing a new term which is goal framing. He introduces the same action but with different goal. For example, when introducing the benefit of exercise, the positive frame will show the benefit of exercise while the negative frame will show the cause and effect of not doing exercise. Gantiva et al (2021) also emphasized that the gain-loss study context (positive-negative) can be adapted in health communication field to test the effectiveness on the readers' change of attitude and behaviour.

Psychology and communication scholars see framing effect studies involve a complex process in psychology namely information processing process. De Vreese (2005) and Reed (1988) explained that news framing was not only seen in the macro perspective but also micro or individually. An individual will receive a message and processed in the cognitive side before it is accepted and giving effect to the change of attitude and behaviour. Attitude refers to a view or thinking towards an issue, or more towards how an individual thinks, feels about something. While behaviour involves more on action and movement towards a matter. The findings of this study show that the significant effect of LGBT news display is only on the change of attitude but not on behaviour. Reed (1988) explained that to ensure the effectiveness to the behaviour, longer and relevant time are needed, for example six months. Therefore, continuous news display is needed to get a consistent effect.

However, some contexts from other perspectives should be considered, such as the readers' previous readings, knowledge, message display interruption and message display frequency. For example, an individual with a negative knowledge of LGBT, will have no effect on positive news display or needs longer time to adapt. Every individual has different level of knowledge, experience, and stand when exposed to positive or negative news message. Future framing effect study needs to focus on these factors in determining the effectiveness of framing. 


\section{Conclusion}

The study of frame determination involves a complex information process that emphasizes the effectiveness on individual's attitude and behaviour. This study emphasizes display that is considered relevant to be used especially in a sensitive issue and less discussed by the society but somehow important. The penetration of message delivery through the new media made this kind of study to be expanded, in helping and educate the society and media practitioners to frame a news in the future.

\section{Acknowledgment}

This research is funded by Research Grant Inisiatif Putra Muda (IPM) with a project title "Kesan Pembingkaian Hate Speech dan Hate Crime melalui digital media: Satu pengujian kepada ekspresi belia (GP-IPM/2018/9665100).

\section{References}

Community Empowerment Organization, CEPO. (2016). Introduction to hate speech on social media. https://defyhatenow.org/wpcontent/uploads/2016/06/defyhatenow_whatishatespeech_JUL27.pdf

De Vreese, C. H. (2005). News framing: Theory and typology. Information Design Journal + Document Design, 13(1), 51-62.

Drozdz, M. (2016). Hate speech in media discourse. Folia Litteraria Polonica, 5(35), 19-30.

Gantiva, C., Leal, W. J., \& Rayo, J. U. (2021). Framing messages to deal with the Covid-19 crisis: The role of loss/gain frames and content. Frontier in Psychology, 12, 1-8.

Jasmi, K. A. (2012). Kursus Penyelidikan Kualitatif Siri 12012 [Paper Presentation]. Institut Pendidikan Guru Malaysia Kampus Temenggong Ibrahim, Johor Bahru, Johor Darul Ta'zim, Malaysia.

Lee, B., \& McLeod, D.M. (2020). Reconceptualizing cognitive media effect theory and research under the judged usability model. Research of Communication Research, 8, 17-38.

McClure, J., White, J., \& Sibley, C. G. (2009), "Framing effects on preparation intentions: distinguishing actions and outcomes", Disaster Prevention and Management, 18(2),187-199. https://doi.org/10.1108/09653560910953252

Mondal, M., Silva, L. A., \& Benevenuto. (2017). Empowerment study of hate speech in social media. 28th ACM Conference on Hypertext and Social Media (HT '17), 85-94. Association for Computing Machinery, New York, NY, USA. https://doi.org/10.1145/3078714.3078723

Phadke, S., \& Mitra, T. (2020). Many faced hate: A cross platform study of content framing and information sharing by online hate groups. Proceeding of the 2020 Conference on Human Factors in Computing System, 1-13. Association for Computing Machinery, New York, NY, USA. https://doi.org/10.1145/3313831.3376456

Reed, S. K. (1988). Cognition, Theory and Applications. California: Library of Congress Cataloguing in Publication Data.

Shafie, M. S., Arif, M. I. A., Hanapi, H., \& Hassan, M. F. (2018); Subsidiary Legislation in Malaysian Administrative Law: Definition, Advantages \& Grounds to Challenge it; International Journal of Scientific and Research Publications, 8(10). http://dx.doi.org/10.29322/IJSRP.8.10.2018.p8238

Shan, L., Diao, H., \& Wu, L. (2020) Influence of the framing effect, anchoring effecr, and consumers' attitude and purchase intention of organic food. Frontiers in Psychology,11, $1-8$. 
INTERNATIONAL JOURNAL OF ACADEMIC RESEARCH IN BUSINESS AND SOCIAL SCIENCES

Vol. 11, No. 19, Youth and Community Wellness, 2021, E-ISSN: 2222-6990 @ 2021 HRMARS

Zawawi, J. W. M., Hasan, H., \& Kho, S. N., Ghazali, A. H. (2021). Information processing through frame setting towards audience cognition on LGBT issues. The European Proceedings of Social and Behavioral Sciences, 10, 186-193.

https://doi.org/10.15405/epsbs.2021.06.02.25 